\title{
ARTIGO
}

\section{PLANTAS MEDICINAIS UTILIZADAS EM RITUAIS DE UMBANDA: ESTUDO DE CASO NO SUL DO BRASIL}

\author{
MEDICAL PLANTS UDED IN UMBANDA RITUALS: \\ A CASE STUDY IN SOUTHERN BRAZIL
}

\begin{abstract}
Maria Eduarda Alves Ferreira', Guilherme Alves Elias², Viviane Kraieski Assunção ${ }^{2}$, Vanilde Citadini-Zanette ${ }^{2 \star}$
\end{abstract}

\section{Resumo:}

A utilização de plantas para fins medicinais é uma prática milenar em todo o mundo. No Brasil, o uso de plantas medicinais em rituais nasceu da miscigenação entre os indígenas, africanos, europeus e seus descendentes, que expandiram para a Umbanda. A religião surgiu no Brasil como uma doutrina única, com influência africana, cristã, espírita e indígena. A utilização dos vegetais nos rituais de Umbanda é diversificada e complexa, ligada diretamente ao conjunto de divindades cultuadas na região, portanto as espécies utilizadas variam muito entre os terreiros. Nesse sentido, este estudo pretendeu registrar as plantas medicinais utilizadas em rituais do Centro Umbandista Pai Tomé e Cabocla Indaiá da Cachoeira (CEUPTCIC), no município de Cocal do Sul, sul de Santa Catarina, Brasil. O levantamento botânico foi realizado por meio de entrevista com a dirigente espiritual da casa, que detém maior conhecimento sobre as plantas consideradas medicinais em seus rituais. Um espécime de cada planta indicada foi coletado para identificação e registro do estudo. Os dados obtidos na entrevista foram comparados com estudos etnobotânicos publicados em diferentes regiões do Brasil. Seis espécies vegetais (Lavandula dentata L., Mentha x rotundifolia (L.) Huds, Petiveria alliacea L., Rosa alba L., Rosmarinus officinalis L. e Ruta graveolens L.) foram mencionadas pela entrevistada para fins terapêuticos e, destas, quatro são aplicadas em seus rituais. $P$. alliacea e $R$. graveolens configuram as espécies mais utilizadas em rituais afro-brasileiros em diferentes regiões do Brasil, presentes em 7 estudos de 10 consultados. Embora tenham sido encontradas referências que respaldam a utilização das espécies no Centro Umbandista, ficou clara a necessidade de maior investigação quanto às patologias dessas espécies indicadas pela entrevistada e não encontradas na literatura.

\footnotetext{
${ }^{1}$ Bióloga, egressa da Universidade do Extremo Sul Catarinense, UNESC, Criciúma, Santa Catarina, Brasil.

${ }^{2}$ Professores do Programa de Pós-Graduação em Ciências Ambientais (PPGCA), Universidade do Extremo Sul Catarinense, UNESC, Criciúma, Santa Catarina, Brasil. * Contato para correspondência: vcz@unesc.net.
} 
Palavras-chave: Etnobotânica; fitoterapia; religião de matriz afro-brasileira; ritual místico-religioso; sul de Santa Catarina.

\begin{abstract}
:
The use of plants for medicinal purposes is an ancient practice. In Brazil, the use of medicinal plants and in rituals was born from the miscegenation among the indigenous, African, European and their descendants, who expanded to Umbanda. The religion emerged in Brazil as a unique doctrine, with African, Christian, Spiritist and indigenous influence. The use of plants in Umbanda rituals is diverse and complex, linked directly to the group of deities worshiped in the region, thus the species used may vary widely among the terreiros. In this sense, the study aimed to record the medicinal plants used in rituals of the Centro Umbandista Pai Tomé e Cabocla Indaiá da Cachoeira (CEUPTCIC), in the municipality of Cocal do Sul, Santa Catarina state, Brazil. The botanical research was accomplished through interview with the spiritual leader of the house, who has the greater knowledge about the medicinal plants used in rituals. One specimen of each indicated plant was collected for identification and registration. The data obtained by the interview was compared with other ethnobotanical studies in different regions of Brazil. Six plant species were presented by the interviewee (Lavandula dentata L., Mentha x rotundifolia (L.) Huds, Petiveria alliacea L., Rosa alba L., Rosmarinus officinalis L. e Ruta graveolens L.) as used for therapeutic purposes, and of these, four are applied in their rituals. $P$. alliacea and $R$. graveolens were the most used species in Afro-Brazilian rituals in different regions of Brazil, present in 7 studies of 10 consulted. Although references were found that support the use of the species at Centro Umbandista, it was evident the need for further investigation regarding the pathologies of these species indicated by the interviewee which is not found in literature.
\end{abstract}

Keywords: Ethnobotany; phytotherapy; afro-Brazilian matrix religion; mysticalreligious ritual; southern Santa Catarina.

\title{
1. Introdução
}

A utilização de plantas como medicamentos é uma prática milenar e, possivelmente, tão antiga quanto a própria humanidade, confundindo-se com sua história de vida (LORENZI e MATOS, 2008; ALMEIDA, 2016). Dependendo basicamente da natureza para a sobrevivência, o ser humano primitivo aprendeu, por meio de tentativas e observações, que algumas espécies agiam de maneira peculiar no funcionamento do seu organismo. A partir dessa constatação, a utilização de plantas com propriedades terapêuticas disseminou-se e se organizou nas mais distintas sociedades, adquirindo particularidades advindas do conhecimento ancestral de cada cultura sobre o poder curativo dos vegetais, além da sua aplicação em cerimônias religiosas (GOMES et al., 2008; CAMARGO, 2014).

No Brasil, a utilização de plantas medicinais e em rituais é resultado de uma miscigenação entre os indígenas locais, as tradições africanas oriundas do tráfico escravo e a cultura europeia trazida pelos colonizadores (CAMARGO, 1976; ALMEIDA, 2016). É comumente atribuída aos povos indígenas a origem de grande parte dos conhecimentos tradicionais sobre plantas medicinais no Brasil (ROCHA e MARISCO, 
2016). Além destes, muitos integrantes de povos escravizados trazidos do continente africano para o Brasil eram feiticeiros e curadores que, por meio de rituais específicos de suas culturas, invocavam auxílio de forças superiores para o aconselhamento sobre problemas de saúde física, mental ou espiritual (SANTOS FILHO, 1991), prática ainda presente nos cultos religiosos de influência africana como a Umbanda (ALBUQUERQUE, 2006).

A Umbanda surgiu no Brasil no início do século XX, em 1908, no Rio de Janeiro, e logo se disseminou por todo o país (CUMINO, 2015). Foi criada como uma religião universal, dirigida a todos, fortemente influenciada por tradições africanas, espíritas, cristãs e indígenas (PRANDI, 1998), tendo como base a caridade e a utilização de entidades da natureza, que são personificados nos orixás (SILVA, 1994) e guias espirituais como os Caboclos (indígenas), Pretos-velhos (negros) e Erês (crianças). A presença de indígenas e negros entre os guias espirituais na Umbanda contribuiu para a formação da identidade cultural brasileira, pois tais entidades apresentam maior proximidade com parte da população que frequenta seus cultos, diferente das vertentes religiosas trazidas pela colonização europeia (CUMINO, 2015).

Devido à fusão das diferentes doutrinas influentes, cada um dos templos umbandistas manifesta diferenças essenciais, que variam de acordo com suas raízes, atribuindo-os características próprias e norteando seus trabalhos (BOTELHO, 2009). Por essa razão, a utilização dos vegetais nos rituais de Umbanda é bastante diversificada e complexa, ligada diretamente ao conjunto de divindades cultuadas na região, ampliando ou diminuindo as espécies utilizadas de um terreiro para o outro ou, em alguns casos, se excluindo (ALBUQUERQUE, 2006). As plantas são empregadas em defumações e preparados especiais com fins específicos, como ritos de amacis, que são personalizados a cada médium ou quando o guia espiritual instrui o consulente para uso de algum chá específico (ARAÚJO, 1973). Os saberes relacionados às plantas estão profundamente associados à concepção de mundo de seus praticantes, e são provenientes das entidades espirituais denominadas orixás (MONTERO, 1979; ALBUQUERQUE e CHIAPPETA, 1994). Os poderes relacionados aos vegetais residem não apenas em sua materialidade, mas em sua interação entre o plano físico e espiritual (CARLESSI, 2015).

No Brasil colonial, a imagem do negro era associada à criminalidade e à indolência e, consequentemente, tudo o que estava ligado a ele - cultura, língua, religião - era visto como negativo e passível de ser combatido (COSTA, 2006). No entanto, o preconceito com rituais de religiões de influência africana continua presente na história do país e muitos praticantes dessas religiões ainda sofrem racismo (MATTOS, 2012). Basta algum símbolo ou adereço característico para sofrerem ataques de violência, discriminação e preconceito, tanto fisicamente quanto psicologicamente e essa intolerância tem aparecido com maior frequência na atualidade (WALMIR JUNIOR, 2016). Uma das prováveis causas dessa discriminação está relacionada ao preconceito racial, atingindo todas as esferas das culturas africana e afro-brasileira (SALES, 2017). Estas posturas discriminatórias desconhecem a importância destas culturas na disseminação de plantas e saberes relacionados a seus usos que são amplamente utilizados por brasileiros (ALBUQUERQUE, 2002).

Portanto, o estudo desse conhecimento tradicional não contribui apenas para a difusão terapêutica dos vegetais, mas também para evitar as imagens negativas que as culturas 
africanas e indígenas ainda possuem na sociedade. Nesse contexto, o presente estudo pretendeu registrar as plantas medicinais utilizadas nos rituais de um Centro Umbandista no município de Cocal do Sul, Santa Catarina, sul do Brasil, a fim de fornecer informações sobre a função das espécies nesses rituais, considerando os aspectos religiosos, etnobotânicos e fitoterápicos.

\section{Materiais e métodos}

O estudo foi realizado no Centro Espírita Umbandista Pai Tomé e Cabocla Indaiá da Cachoeira (CEUPTCIC), localizado no município de Cocal do Sul, sul do estado de Santa Catarina, na latitude $28^{\circ} 36^{\prime} 6^{\prime \prime}$ Sul e longitude: 49 19' 35" Oeste - sede (CIDADE BRASIL, 2018).

O Centro foi trazido à manifestação terrena, ou seja, tendo uma sede física própria, no ano de 2011 como instituição religiosa sem fins lucrativos, todavia foi registrado oficialmente como Templo Religioso para fins burocráticos apenas em 2012, segundo Fagundes (2015). O CEUPTCIC trabalha espiritualmente com as Sete Linhas de Umbanda, que são: Obaluauê, Iemanjá, Ogum, Xangô, Iansã, Oxum e Oxossi. Não há qualquer tipo de custo nos atendimentos realizados no Centro, sendo que estes são em forma de consultas individuais dos consulentes com os guias espirituais da casa em dias específicos. Ao final dos cultos ocorre as chamadas "giras de trabalho", realizadas uma vez por semana.

A pesquisa consistiu em um estudo de campo com abordagem quanti-qualitativa, realizada por meio de entrevista semiestruturada (ALBUQUERQUE et al., 2010), sendo aplicado um formulário, previamente elaborado, com questões que possibilitaram a discussão do assunto (BONI e QUARESMA, 2005). O formulário foi dividido em duas partes: (i) coleta de dados pessoais do participante (sexo, estado civil, escolaridade, naturalidade, religião) e (ii) coleta de dados da espécie vegetal (nome popular e/ou científico, parte da planta utilizada e forma de utilização).

A entrevista foi realizada com a dirigente espiritual do Templo Umbandista, considerada, pelo questionamento prévio realizado, a maior detentora de conhecimento sobre plantas com uso medicinal nos rituais (ALBUQUERQUE et al., 2010). O estudo foi submetido ao Comitê de Ética em Pesquisa com Seres Humanos (CEP) da UNESC para realização da entrevista e aprovado sob o Parecer 2.253.201.

Todas as espécies vegetais utilizadas nos rituais, citadas pela entrevistada, foram coletadas, identificadas e herborizadas (mesmo em estado vegetativo), exsicatadas (exemplar prensado e desidratado para catalogação) com número de registro e, em seguida, incorporadas ao acervo do Herbário Pe. Dr. Raulino Reitz (CRI) da Universidade do Extremo Sul Catarinense (UNESC). Os nomes científicos foram atualizados pela consulta ao site World Flora Online (WFO, 2020), para confirmação do nome válido e evitar as sinonímias. A coleta das plantas foi realizada no Centro Umbandista, onde as plantas são cultivadas.

Após o levantamento, os dados obtidos na entrevista foram analisados por meio de comparação com artigos científicos publicados em diferentes regiões do Brasil, visando a saber se as espécies usadas no CEUPTCIC variam nas diferentes regiões fisiográficas e quais as mais utilizadas nos rituais afro-brasileiros. Na busca para a pesquisa foram utilizados os termos: plantas ritualísticas, umbanda, a nomenclatura científica e 
sinonimias das espécies registradas neste estudo e utilizadas em rituais afrobrasileiros.

\section{Resultados e discussão}

\subsection{Perfil do entrevistado}

A entrevistada é natural do município de Criciúma, Santa Catarina, e residente no município de Cocal do Sul, casada e com ensino superior completo em Psicologia. Seu primeiro contato com plantas medicinais e ritualísticas foi há 10 anos por meio da Umbanda e de seus guias espirituais. A interrogada relata que o papel das plantas é fundamental na arte de curar e benzer. Seu conhecimento sobre a aplicação das plantas foi adquirido por meio dos guias espirituais, o qual é repassado aos médiuns e consulentes que frequentam o CEUPTCIC. As plantas utilizadas nos rituais são cultivadas no terreiro do Centro de Umbanda, nas casas de outros médiuns ou compradas em floriculturas e viveiros. Quando questionada sobre o uso de plantas medicinais pelos profissionais de saúde, declarou ser "perfeito", pois acredita que esse será o futuro da medicina.

\subsection{Plantas medicinais e utilizadas nos rituais}

Os rituais estão ligados ao conceito de execução que constitui modos de melhor utilizar as plantas para que se possa absorver o poder místico da espécie em forma de amuletos, chás, defumações ou banhos, unindo o mágico com as propriedades medicinais das espécies (CAMARGO, 2015; ALMEIDA, 2016). Além da presença dessas propriedades, estudos sobre os componentes simbólicos dos rituais admitem que os símbolos e as representações acionadas nesses eventos atuem na ressignificação e transformação das condições do consulente, contribuindo para o processo de cura e superação das adversidades (LÉVI-STRAUSS, 1975; LAPLANTINE, 1995; TURNER, 2013).

No Centro Espírita Umbandista Pai Tomé e Cabocla Indaiá da Cachoeira (CEUPTCIC) os vegetais são escolhidos de acordo com o que é encontrado na região e pelo saber regional, associado ao tipo de ritual. Para este estudo foram apresentadas pela entrevistada seis espécies vegetais com fins terapêuticos (Tabela 1), entre elas quatro são aplicadas em seus rituais (Tabela 2). As espécies citadas e escolhidas, segundo a umbandista, são as mais comumente solicitadas pelos guias espirituais e também as que se encontram disponíveis no terreiro.

Tabela 1 - Espécies utilizadas para fins terapêuticos no Centro Espírita Umbandista Pai Tomé e Cabocla Indaiá da Cachoeira (CEUPTCIC), com informações da entrevistada quanto as indicações terapêuticas e modos de uso.

\begin{tabular}{|c|c|c|c|}
\hline FAMÍLIA/ nome científico & Nome popular & Indicações Terapêuticas & Modo de usar \\
\hline \multicolumn{4}{|l|}{ LAMIACEAE } \\
\hline Lavandula dentata $\mathrm{L}$. & Lavanda/alfazema & $\begin{array}{l}\text { Uso externo: pele, cabelo, } \\
\text { piolhos, psoríase, sarna, } \\
\text { eczemas, cicatrizante e } \\
\text { dores reumáticas. Uso } \\
\text { interno: asma, tosse, } \\
\text { sinusite, bronquite, insônia, } \\
\text { flatulência, vertigens e } \\
\text { enxaquecas, combate à }\end{array}$ & $\begin{array}{l}\text { Uso externo: planta toda } \\
\text { usada em banhos. Uso } \\
\text { interno: usam-se as } \\
\text { sumidades floridas } \\
\text { secas para chá. }\end{array}$ \\
\hline
\end{tabular}




\begin{tabular}{|c|c|c|c|}
\hline & & $\begin{array}{l}\text { depressão, calmante, cólicas } \\
\text { intestinais, fígado e } \\
\text { problemas de baço. }\end{array}$ & \\
\hline $\begin{array}{l}\text { Mentha x rotundifolia (L.) } \\
\text { Huds }\end{array}$ & Hortelã & $\begin{array}{c}\text { Uso externo: aplicado em } \\
\text { nevralgias, dores de cabeça e } \\
\text { dente e picadas de insetos. } \\
\text { Uso interno: digestão, } \\
\text { náuseas, cólicas, gases, bílis, } \\
\text { amarelão, expectorante, } \\
\text { insônia, calmante e } \\
\text { vermífuga. }\end{array}$ & $\begin{array}{c}\text { Uso externo: sumo das } \\
\text { folhas pode ser aplicado } \\
\text { no local com algodão. } \\
\text { Para vermes: adicionar } \\
\text { mel ao sumo e tomar por } \\
\text { vários dias. Uso interno: } \\
\text { chá das folhas de } \\
\text { hortelã. }\end{array}$ \\
\hline Rosmarinus officinalis L. & Alecrim & $\begin{array}{c}\text { Uso externo: cabelo, caspa e } \\
\text { pele. Uso interno: histeria, } \\
\text { nervosismo, clorose, } \\
\text { indigestão, bronquite, asma, } \\
\text { tosse, inapetência, } \\
\text { sudorífica, antirreumática, } \\
\text { depurativo do sangue e } \\
\text { tônica. }\end{array}$ & $\begin{array}{l}\text { Uso externo: banhos das } \\
\text { folhas. Uso interno: chá } \\
\text { das folhas. }\end{array}$ \\
\hline \multicolumn{4}{|l|}{ PHYTOLACCACEAE } \\
\hline Petiveria alliacea L. & guiné & $\begin{array}{c}\text { Uso externo: dores } \\
\text { reumáticas, artrite, artrose, } \\
\text { nevralgias, dores no corpo, } \\
\text { cabeça e dente. Uso interno: } \\
\text { laringite, dores na garganta e } \\
\text { gengivites. }\end{array}$ & $\begin{array}{l}\text { Uso externo: } 100 \text { gramas } \\
\text { de folhas ou raiz em } 1 / 2 \\
\text { litro de álcool e deixar } \\
\text { curtir por } 3 \text { dias; após, } \\
\text { massagear o local } \\
\text { desejado. Uso interno: } \\
\text { chá da raiz ou folhas e } \\
\text { fazer gargarejos. }\end{array}$ \\
\hline \multicolumn{4}{|l|}{ ROSACEAE } \\
\hline Rosa alba L. & rosa-branca-pequena & $\begin{array}{l}\text { Uso externo: inflamações, } \\
\text { irritação dos olhos, aftas, } \\
\text { queimaduras, hemorroidas, } \\
\text { abcesso e manchas na pele. } \\
\text { Uso interno: calmante, } \\
\text { adstringente, digestivo, } \\
\text { equilibra o sono e laxativo }\end{array}$ & $\begin{array}{l}\text { Uso externo: compressas } \\
\text { do chá das pétalas. Uso } \\
\underline{\text { interno: chá das pétalas. }}\end{array}$ \\
\hline \multicolumn{4}{|l|}{ RUTACEAE } \\
\hline Ruta graveolens L. & arruda & $\begin{array}{c}\text { Uso externo: dor de cabeça, } \\
\text { dor de dente e de ouvido. Uso } \\
\text { interno: flatulência, } \\
\text { calmante, fraqueza dos } \\
\text { vasos sanguíneos, } \\
\text { indigestão, ressaca e } \\
\text { embriaguez, incontinência } \\
\text { urinária e anti-infecciosa. }\end{array}$ & $\begin{array}{c}\text { Uso externo: para dor de } \\
\text { cabeça esfregar folha na } \\
\text { testa; para dor de dente e } \\
\text { ouvido fazer sumo dos } \\
\text { ramos e aplicar no local } \\
\text { com algodão. Uso } \\
\text { interno: apenas uma } \\
\text { colher de chá da flor ou } \\
\text { folha para uma xícara de } \\
\text { água. Evitar uso na } \\
\text { gravidez. }\end{array}$ \\
\hline
\end{tabular}

Fonte: Elaboração própria.

Tabela 2 - Espécies utilizadas em rituais para fins terapêuticos espiritual no Centro Espírita Umbandista Pai Tomé e Cabocla Indaiá da Cachoeira (CEUPTCIC).

\begin{tabular}{lccc}
\hline FAMILIA/ nome cientifico & Nome popular & Uso Ritualístico & Modos de usar \\
\hline LAMIACEAE & & & \\
\hline Lavandula dentata L. & lavanda/alfazema & $\begin{array}{c}\text { Acalmadora do espírito, } \\
\text { tranquiliza as situações } \\
\text { difíceis. Harmonia. }\end{array}$ & Banhos e defumações. \\
& & Estimulante para todos os & Banhos e defumações. \\
& hortelã & sentidos da vida, equilíbrio, & \\
& & abre caminhos, levanta o & \\
& & &
\end{tabular}




\begin{tabular}{lccc}
\hline Rosmarinus officinalis L. & astral e atrai boa sorte. & \\
\hline ROSACEAE & rosa-branca-pequena & $\begin{array}{c}\text { Equilíbrio, rejuvenescimento, } \\
\text { alegria, clarear e iluminar os } \\
\text { pensamentos. }\end{array}$ & Banhos e defumações. \\
\hline Rosa alba L. & $\begin{array}{c}\text { Apaziguadora de espírito, } \\
\text { auxilia no desenvolvimento } \\
\text { psíquico, purificadora dos } \\
\text { chakras. }\end{array}$ & $\begin{array}{c}\text { Amacis, banhos, bebidas } \\
\text { ritualísticas. }\end{array}$ \\
& & & \\
\hline
\end{tabular}

Fonte: Elaboração própria.

Conforme a dirigente espiritual entrevistada, a lavanda (Lavandula dentata) possui uma energia vibratória tranquilizadora, trazendo paz de espírito para resolver os problemas do dia-a-dia. É comumente utilizada para desenvolvimento e preparação dos médiuns, geralmente na forma de banhos e defumações, que servem para limpeza do terreiro, do corpo mediúnico e da assistência, sendo indicada pelos Guias espirituais para tratamento de males físicos e espirituais.

O uso da lavanda pelos umbandistas vai ao encontro de estudos realizados em comunidades tradicionais e população em geral para tratar cólicas intestinais, problemas hepáticos (JAMILA e MOSTAFA, 2014; MIKOU et al., 2016; TEIXIDOR-TONEU et al., 2016), doenças dermatológicas e respiratórias (TEIXIDOR-TONEU et al., 2016), dor no baço, insônia e ansiedade (MIKOU et al., 2016). Embora citado pela entrevistada o uso da espécie para cabelo, piolhos, sarna, eczemas, cicatrizante e dores reumáticas, insônia, flatulência, vertigens e enxaquecas, combate à depressão, calmante e problemas de baço, não foram encontrados estudos que ratificam essa utilização.

A hortelã (Mentha x rotundifolia), no CEUPTCIC, é usada para fortalecer o espírito, dar ânimo e coragem, é energizadora, estimulante estabilizadora da energia vital, utilizada em banhos e, quando seca, em defumações. A espécie não é muito popular na fitoterapia e em apenas um estudo (NEVES et al., 2009) foi descrita a mesma indicação relatada pela entrevistada. Estes autores realizaram estudo com os moradores da região de Trás-os-Montes, no norte de Portugal, que relataram a utilização da planta para aliviar problemas digestivos.

Na busca por publicações etnobotânicas e de uso popular de Mentha x rotundifolia não foram encontradas, nos artigos consultados, informações sobre os usos mencionados pela entrevistada (Tabela 1), o que evidencia ainda o pouco conhecimento sobre a espécie.

O alecrim (Rosmarinus officinalis) é muito utilizado no CEUPTCIC para indicação de banhos e defumações, sendo extremamente equilibradora e tranquilizadora. Associada a outras ervas, dá consistência e estabilidade ao preparo. Em estudo realizado por Geck et al. (2016) com comunidades Zoque, no México, demonstraram que a planta é utilizada pelo povo para expulsar espíritos malignos. Primeiramente é preparada uma maceração alcoólica, que é ingerida e depois expulsa em forma de vômito sobre a face e corpo do doente.

Rosmarinus officinalis, por ser uma planta de conhecimento muito antigo, é uma das mais utilizadas em diferentes regiões do mundo e seu uso é diversificado. O uso medicinal da espécie pelos umbandistas é mencionado em outros estudos para tratamento de problemas pulmonares (CADENA-GONZÁLEZ et al., 2013; BENARBA, 2016; MIKOU et al., 2016; BIESKI et al., 2015; EDDOUKS et al., 2017), cabelo (CADENA-GONZÁLEZ 
et al., 2013; EDDOUKS et al., 2017), reumatismo (CADENA-GONZÁLEZ et al., 2013; EDDOUKS et al., 2017), indigestão (ANDRADE-CETTO, 2009; CORNARA et al., 2009; CADENA-GONZÁLEZ et al., 2013; BENARBA, 2016; ALVES-SILVA et al., 2017), nervosismo e clorose (MIKOU et al., 2016), depurativo do sangue (CORNARA et al., 2009) e doenças de pele (EDDOUKS et al., 2017). O alecrim também é utilizado pela entrevistada para tratar histeria, inapetência, sudorífica e tônica. No entanto, na pesquisa realizada, não há registro de utilização desta espécie para estas funções terapêuticas.

A guiné (Petiveria alliacea) é indicada no CEUPTCIC tanto para uso externo, como interno, para tratamento de diferentes males. Por meio de pesquisa bibliográfica, foi constatado semelhança na aplicação da espécie em diferentes regiões geográficas, por diferentes grupos tradicionais, para reumatismo (ALBUQUERQUE et al., 2007; BIESKI et al., 2012; QUIROGA et al., 2012; BIESKI et al., 2015), dores no corpo (ALBUQUERQUE et al., 2007; BIESKI et al. 2015) e garganta (BIESKI et al., 2015). Foi relatado também o emprego de P. alliacea para tratamento de artrite, artrose, nevralgias, dores de cabeça e dente, laringite e gengivites, indicações das quais não foram encontrados estudos que corroboram estes usos.

A guiné, também conhecida como "amansa senhor" por ser empregada pelos negros do período escravagista do Brasil no preparo de uma bebida, foi administrada secretamente por tempo prolongado aos senhores de escravos, levando-os a perturbações mentais que visavam principalmente proteger as mulheres negras do assédio de seus patrões (CAMARGO, 2007; ALMEIDA, 2016).

A rosa-branca (Rosa alba), no CEUPTCIC, serve de oferenda para os orixás Oxalá e Iemanjá, podendo ser usada em todos os amacis e nas ornamentações festivas, pois compõe verdadeira honra para todos os orixás (divindades). Possui capacidade apaziguadora de espírito, auxilia no desenvolvimento psíquico, purifica os chakras, em especial o coronal, o frontal e o cardíaco, estabelecendo, assim, forte conexão com o plano espiritual. É utilizada, principalmente, em banhos. Seu uso pelos umbandistas do CEUPTCIC ratifica estudos etnobotânicos para o tratamento de abcessos (BIESKI et al., 2015), aftas (OLIVEIRA e MENINI NETO, 2012) e manchas na pele (PIERONI, 2017).

A rosa-branca é utilizada no CEUPTCIC para outros males, como: inflamações, irritação dos olhos, queimaduras, hemorroidas, calmante, adstringente, digestivo, para equilibrar o sono e como laxativa. Todavia, não foram encontrados registros nas bases de dados consultadas para estes agravos à saúde.

Conforme declarado na entrevista, o uso interno da arruda (Ruta graveolens) no CEUPTCIC é feito de forma controlada, pois, segundo a entrevistada, a espécie apresenta certo nível de toxicidade, sendo evitada na gravidez. Ainda assim, alguns dos seus usos foram mencionados em outros estudos etnobotânicos para infecções (LEMOS et al., 2016), indigestão (ALONSO-CASTRO et al., 2012; LIPORACCI e SIMÃO, 2013; ZEGGWAGH et al., 2013; VITALINI et al., 2015; KOSIC et al., 2017), calmante (ALONSOCASTRO et al., 2012; VITALINI et al., 2015; KOSIC et al., 2017), dores-de-cabeça (LIPORACCI e SIMÃO, 2013; OLIVEIRA et al., 2015; ANDRADE et al., 2017), dor-de-ouvido (ALONSO-CASTRO et al., 2012; RIBEIRO et al., 2014) e dor-de-dente (ALONSO-CASTRO et al., 2012).

A arruda também é indicada no CEUPTCIC para o tratamento de flatulência, fraqueza dos vasos sanguíneos, ressaca, embriaguez e incontinência urinária, mas, para tais males, não foram encontrados levantamentos etnobotânicos publicados em artigos que 
atestam tal efeito. Embora não mencionado pela entrevistada, a arruda possui um forte componente simbólico relacionado à proteção espiritual (MAIOLI-AZEVEDO e FONSECA-KRUEL, 2007; ALMEIDA, 2016).

Quando comparado os dados obtidos neste estudo com outros que tratam de plantas ritualísticas, evidencia-se a preferência de Petiveria alliacea e Ruta graveolens como as espécies mais utilizadas em rituais afro-brasileiros em diferentes regiões do Brasil, presentes em sete estudos de dez consultados (SCARPA e GUERCI, 1987; CAMARGO, 1988; ALBUQUERQUE e CHIAPPETTA, 1994; ALBUQUERQUE, 2006; MAIOLI-AZEVEDO e FONSECA-KRUEL, 2007; CAMARGO, 2014; PAZ et al., 2015; ALMEIDA, 2016; ALVES et al., 2019), seguida de Rosmarinus officinalis presente em seis estudos e Rosa alba apenas em um estudo. Lavandula dentata e Mentha x rotundifolia não foram encontradas nestes estudos, evidenciando menor presença na prática religiosa de matriz africana, embora a segunda espécie às vezes mencionadas como Mentha spp. e, de acordo com Lorenzi e Matos (2008), L. dentata é a espécie mais adaptada e cultivada no Brasil e que, possivelmente, tenha as mesmas propriedades de Lavandula officinalis L. (L. angustifolia Mill., nome atualizado), utilizada nos rituais afro-brasileiros nas buscas bibliográficas realizadas.

\section{Conclusão}

A Umbanda é uma religião essencialmente brasileira, expandida por quase todo o país, que possui forte conexão com a natureza e faz dela seu templo. Desde a Antiguidade, muitas plantas são utilizadas em rituais místicos. O presente estudo revelou que algumas espécies são preferencialmente usadas para estes objetivos devido ao seu poder energético e pela associação aos orixás.

A correta identificação botânica de plantas medicinais destaca-se como relevante neste processo, pois pode evitar o uso indevido da planta e possíveis intoxicações. Basear-se em nomes populares pode ser arriscado, pois duas espécies podem ter o mesmo nome popular em diferentes regiões geográficas ou dentro da mesma região (CITADINI-ZANETTE e MARTINS, 2011). Além do reconhecimento correto, o manejo utilizado no cultivo das plantas exerce forte influência na produtividade da planta e no teor dos princípios bioativos.

Apesar de serem encontrados vários estudos etnobotânicos que respaldam a utilização das espécies no CEUPTCIC, como a presença de Petiveria aliacea e Ruta graveolens em $70 \%$ dos estudos consultados, ficou clara a necessidade de maior investigação quanto às patologias indicadas pela entrevistada e não encontradas na literatura. Um exemplo é a Mentha x rotundifolia, que apresentou o menor número de estudos. Tal resultado pode estar relacionado à difícil identificação botânica de espécies do gênero Mentha, o que serve de alerta para o uso correto da espécie, quando utilizada para fins medicinais. Esta constatação evidencia a necessidade de mais estudos sobre $M$. x rotundifolia.

Os guias espirituais que atuam nos terreiros são escravos, indígenas, ciganos, entre outros, que possuem um poder imensurável: a riqueza do saber. A pesquisa sobre esse conhecimento é de tal relevância, não somente no meio acadêmico, mas para melhor compreensão de tais práticas e, dessa forma, quebrar paradigmas enraizados na sociedade relacionados à Umbanda. A valorização deste saber é fundamental para o 
avanço da ciência. Diante disso, destaca-se o mérito da etnobotânica e da etnofarmacologia como forma de resgatar os saberes tradicionais.

\section{Referências -}

ALBUQUERQUE, U. P. Introdução à etnobotânica. Recife: Bagaço, 2002. 87 p.

ALBUQUERQUE, U. P. Folhas sagradas: as plantas litúrgicas e medicinais nos cultos afro-brasileiros. 2 ed. Recife: Nupeea, 2006. 195 p.

ALBUQUERQUE, U. P.; CHIAPPETA, A. A. O uso de plantas e a concepção de doença e cura nos cultos afro-brasileiros. Ciência \& Trópico, Recife, v. 22, n. 2, p.197-210, 1994.

AlBUQUerque, U. P.; MONTEIRO, J. M.; RAMOS, M. A.; AMORIM, E. L. C. Medicinal and magic plants from a public market northeastern Brazil. Journal of Ethnopharmacology, Pretoria, v. 110, n. 1, p.76-91, 2007.

ALBUQUERQUE, U. P.; LUCENA, R. F. P.; LINS NETO, E. M. F. Seleção dos participantes da pesquisa. In: ALBUQUERQUE, U. P.; LUCENA, R. F. P.; CUNHA, L. V. F. C. (Org.). Métodos e técnicas na pesquisa etnobiológica e etnoecológica, Recife: Nupeea, 2010, p. 21-37.

ALMEIDA, M. Z. Plantas medicinais, 4 ed. Salvador: EDUFBA, 2016, 213 p.

ALONSO-CASTRO, A. J.; MALDONADO-MIRANDA, J. J.; ARATE-MARTINEZ, A.; JACOBOSALCEDO, M. R.; FERNÁNDEZ-GALICIA, C.; FIGUEROA-ZUÑIGA, L. A.; RIOS-REYES, N. A.; LEÓN-RUBIO, M. A.; EDELLÍN-CASTILLO, N. A.; REYES-MUNGUIA, A.; MÉNDEZMARTÍNEZ, R.; CARRANZA-ALVAREZ, C. Medicinal plants used in the Huastecapotosina, México. Journal of Ethnopharmacology, Pretoria, v. 143, p. 292-298, 2012.

ALVES-SILVA, J. M.; ROMANE, A.; EFFERTH, T.; SALGUEIRO, L. North african medicinal plants traditionally used in cancer therapy. Frontiers in Pharmacology, Davis, v. 8, n. 383, p. 1-24, 2017.

ALVES, K. C. H.; POVH, J. A.; PORTUGUEZ, A. P. Etnobotânica de plantas ritualísticas na prática religiosa de matriz africana no município de Ituiutaba, Minas Gerais, Brasil. Ethnoscientia, Altamira, v. 4, n. 1, p. 1-10, 2019.

ANDRADE-CETTO, A. Ethnobotanical study of the medicinal plants from Tlanchinol, Hidalgo, México. Journal of Ethnopharmacology, Pretoria, v. 122, p. 163-171, 2009.

ANDRADE, J. M.; MOSQUERA, H. L.; ARMIJOS, C. Ethnobotany of indigenous saraguros: medicinal plants used by community healers "hampiyachakkuna" in the San Lucas parish, Southern Ecuador. Biomed Research International, London, v. 2017, p. 1-20, 2017.

ARAÚJO, A. M. Cultura popular brasileira. São Paulo: Melhoramentos, 1973, 193 p.

BENARBA, B. Medicinal plants used by traditional healers from south-west Algeria: an ethnobotanical study. Journal of Intercultural Ethnopharmacology, Nashville, n. 4, p. 220-330, 2016.

BIESKI, I. G. C.; SANTOS, F. R.; OLIVEIRA, R. M.; ESPINOSA, M. M.; MACEDO, M.; ALBUQUERQUE, U. P.; MARTINS, D. T. O. Ethnopharmacology of medicinal plants of the pantanal region (Mato Grosso, Brazil). Evidence-based complementary and alternative medicine, v. 2012, p. 1-36, 2012. 
BIESKI, I. G. C.; LEONTI, M.; ARNASON, J. T.; FERRIER, J.; RAPINSKI, M.; VIOLANTE, I. M. P.; BALOGUN, S. O.; PEREIRA, J. F. C. A.; FIGUEIREDO, R. C. F.; LOPES, C. R. A. S.; SILVA, D. R.; PACINI, A.; ALBUQUERQUE, U. P.; MARTINS, D. T. O. Ethnobotanical study of medicinal plants by population of valley of Juruena region, legal Amazon, Mato Grosso, Brazil. Journal of Ethnopharmacology, Pretoria, v. 173, p. 383-423, 2015.

BONI, V.; QUARESMA, S. J. Aprendendo a entrevistar: como fazer entrevistas em ciências sociais. Revista Eletrônica dos Pós-graduandos em Sociologia Política da UFSC, Florianópolis, v. 2, n. 1, p. 68-80, 2005.

BOTELHO, J. Apostila de estudo: umbanda - estudo básico. Rio de janeiro: TEDES Tenda Espírita Divino Espírito Santo, 2009. 94 p.

CADENA-GONZÁLEZ, A. L.; SORENSEN, M.; THEILADE, J. Use and valuation of native and introduced medicinal plant species in campo hermoso and zetaquira, Boyacá, Colombia. Journal of Ethnobiology and Ethnomedicine, Nashville, v. 9, n. 23, p. 1-14, 2013.

CAMARGO, A. Rituais com ervas: banhos, defumações e benzimentos. 4 ed., São Paulo: Livre Expressão, 2015. 216 p.

CAMARGO, M. T. L. A. Medicina popular. Rio de Janeiro: MEC/ Campanha de Defesa do Folclore Brasileiro, 1976. 40 p.

CAMARGO, M. T. L. A. Plantas medicinais e de rituais afro-brasileiros I. São Paulo: Almed, 1988.

CAMARGO, M. T. L. A. AMANSA-SENHOR: a arma dos negros contra seus senhores. Revista Pós Ciências Sociais, São Luís, v. 4, n. 8, p. 31-42, 2007.

CAMARGO, M. T. L. A. As plantas medicinais e o sagrado: a etnofarmacobotânica em uma revisão historiográfica da medicina popular no Brasil. São Paulo: Ícone, 2014. 264 p.

CARLESSI, P. C. Dimensão e fluxo material das plantas em um terreiro de umbanda. Avá. Revista de Antropología, Misiones, n. 27, p. 47-62, 2015.

CIDADE BRASIL. Município de Cocal do Sul. Disponível em: https://www.cidadebrasil.com.br/municipio-cocal-do-sul.html. Acesso em: 11 jul. 2018.

CITADINI-ZANETTE, V.; MARTINS, R. Identificação botânica: ênfase plantas medicinais. Caderno Técnico-Didático, ACPM: 7-23, 2011.

CORNARA, L.; ROCCA, A.; MARSILI, S.; MARIOTTI, M. G. Tradicional uses of plants in the eastern riviera (Liguria, Italy). Journal of Ethnopharmacology, Pretoria, V. 125, p. 16-30, 2009.

COSTA, S. Dois atlânticos: teoria social, antirracismo, cosmopolitismo. Belo Horizonte: UFMG, 2006. 267 p.

CUMINO, A. História da umbanda: uma religião brasileira. São Paulo: Madras, 2015. 400 p.

EDDOUKS, M.; AJEBLI, M.; HEBI, M. Ethnopharmacological survey of medicinal plants used in daraa-tafilalet region (Province of Errachidia), Morocco. Journal of Ethnopharmacology, Pretoria, v. 198, p. 516-530, 2017.

FAGUNDES, D. G. Cartilha do médium do Centro Espírita Umbandista Pai Tomé e Cabocla Indaiá da Cachoeira. Documento particular, 2015. 43 p. 
GECK, M. S.; GARCÍA, A. J. R.; CASU, L.; LEONTI, M. Acculturation and ethnomedicine: a regional comparison of medicinal plant knowledge among the Zoque of Southern Mexico. Journal of Ethnopharmacology, Pretoria, v. 187, p. 146-159, 2016.

GOMES, H. H. S.; DANTAS, I. C.; CATÃO, M. H. C. V. Plantas medicinais: sua utilização em terreiros de Umbanda e Candomblé na zona leste da cidade de Campina Grande - PB. Revista Brasileira de Biologia e Farmácia, Campina Grande, v. 3, n. 1, p. 110-129, 2008.

JAMILA, F.; MOSTAFA, E. Ethnobotanical survey of medicinal plants used by people in oriental Morocco to manage various ailments. Journal of Ethnopharmacology, Pretoria, v. 154, p. 76-87, 2014.

KOSIC, J. V.; JURACAK, J.; LUCZAJ, L. Using Ellenberg-Pignatti values to estimate habitat preferences of wild food and medicinal plants: an example from Northeastern Istria (Croatia). Journal of Ethnobiology and Ethnomedicine, Nashville, v. 113, n. 31, p. 119, 2017.

LAPLANTINE, F. Aprender antropologia. São Paulo: Editora Brasiliense, 1995. 206 p.

LEMOS, I. C. S.; DELMONDES, G. A.; SANTOS, A. D. F.; SANTOS, E. S.; OLIVEIRA, D. R.; FIGUEIREDO, P. R. L.; ALVES, D. A.; BARBOSA, R.; MENEZES, I. R. A.; COUTINHO, H. D. M.; KERNTOPF, M. R.; FERNANDES, G.P. Ethnobiological survey of plants and animals used for the treatment of acute respiratory infections in children of a traditional community in the municipality of Barbalha, Ceará, Brazil. African Journal of Traditional, Complementary and Alternative Medicines, v. 13, n. 4, p. 166-175, 2016.

LÉVI-STRAUSS, C. A eficácia simbólica. In: LÉVI-STRAUSS, C. Antropologia estrutural. Rio de Janeiro: Tempo Brasileiro, 1975. p. 215-236.

LIPORACCI, H. S. N.; SIMÃO, D. G. Levantamento etnobotânico de plantas medicinais nos quintais do bairro Novo Horizonte, Ituiutaba, MG. Revista Brasileira de Plantas Medicinais, Campinas, v. 15, n. 4, p. 529-540, 2013.

LORENZI, H.; MATOS, F. J. A. Plantas medicinais no Brasil: nativas e exóticas cultivadas. 2. ed. Nova Odessa: Instituto Plantarum, 2008. 564 p.

MAIOLI-AZEVEDO, V.; FONSECA-KRUEL, V. S. Plantas medicinais e ritualísticas vendidas em feiras livres no município de Rio de Janeiro, RJ, Brasil: estudo de caso nas zonas norte e sul. Acta Botanica Brasilica, São Paulo, v. 2, n. 21, p. 263-275, 2007.

MATTOS, R. A. História e Cultura afro-brasileira-Brasileira. 2. ed. São Paulo: Contexto, 2012. 224 p.

MIKOU, K.; RACHIQ, S.; OULIDI, A. J. Étude ethnobotanique des plantes médicinales et aromatiques utilizees dans la ville de Fès au Maroc. Phytothérapie, v. 14, n. 1, p. 35-43, 2016.

MONTERO, P. Umbanda: a doença e o corpo. Ciência \& Cultura, Campinas, v. 31, n. 1, p. 25-31, 1979.

NEVES, J. M.; MATOS, C.; MOUTINHO, C.; QUEIROZ, G.; GOMES, R. L. Ethnopharmacological notes about ancient uses of medicinal plants in Trás-os-Montes (Northern of Portugal). Journal of Ethnopharmacology, Pretoria, v. 124, n. 2, p. 270-283, 2009 . 
OLIVEIRA, D. R.; KRETTLI, A. U.; AGUIAR, A. C. C.; LEITÃO, G. G.; VIEIRA, M. N.; MARTINS, K. S.; LEITÃO, S. G. Ethnopharmacological evaluation of medicinal plants used against malária by quilombola communities from oriximiná, Brazil. Journal of Ethnopharmacology, Pretoria, v. 173, p. 424-434, 2015.

OLIVEIRA, E. R.; MENINI NETO, L. Levantamento etnobotânico de plantas medicinais utilizadas pelos moradores do povoado de manejo, Lima Duarte - MG. Revista Brasileira de Plantas Medicinais, Campinas, v. 14, n. 2. p. 311-320, 2012.

PAZ, C. E.; LEMOS, I. C. S.; MONTEIRO, A. B.; DELMONDES, G. A.; FERNANDES, G. P.; COUTINHO, H. D. M.; FELIPE, C. F. B.; MENEZES, I. R. A.; KERNTOPF, M. R. Plantas medicinais no candomblé como elemento de resistência cultural e cuidado à saúde. Revista Cubana de Plantas Medicinales, Havana, v. 20, n. 1, p. 25-37, 2015.

PIERONI, A. Traditional uses of wild food plants, medicinal plants, and domestic remedies in Albanian, Romanian and Macedonian villages in south-eastern Albania. Journal of Herbal Medicine, v. 9, p. 81-90, 2017.

PRANDI, R. Referências sociais das religiões afro-brasileiras: sincretismo, branqueamento, africanização. Horizontes Antropológicos, Porto Alegre, v. 4, n. 8, p. 151$167,1998$.

QUIROGA, R.; MENESES, L.; BUSSMANN, R. W. Medicinal ethnobotany in Huacareta (Chuquisaca, Bolivia). Journal of Ethnobiology and Ethnomedicine, Nashville, v. 8, n. 29, p. 1-14, 2012.

RAINHO, D. Guia do umbandista. 2016. Disponível em: http://perdido.co/wpcontent/uploads/2016/12/guia-do-umbandista.pdf. Acesso em: 05 nov. 2019.

RIBEIRO, D. A.; MACÊDO, D. G.; OLIVEIRA, L. G. S.; SARAIVA, M. E.; OLIVEIRA, S. F.; SOUZA, M. M. A.; MENEZES, I. R. A. Potencial terapêutico e uso de plantas medicinais em uma área de caatinga no estado do Ceará, nordeste do Brasil. Revista Brasileira de Plantas Medicinais, Campinas, v. 16, n. 4, p. 912-930, 2014.

ROCHA, R.; MARISCO, G. Estudos etnobotânicos em comunidades indígenas no Brasil. Revista Fitos, Rio de Janeiro, v. 10, n. 2, p. 95-219, 2016.

SALES, V. A. 2017. Umbanda: preconceito e similaridades. 2017. 69 f. Trabalho de Conclusão de Curso (Gestão de Projetos Culturais e Organização de Eventos) Faculdade Cásper Líbero, Universidade de São Paulo, São Paulo.

SANTOS FILHO, L. História geral da medicina brasileira. São Paulo: HUCITEC/EDUSP, 1991. $436 \mathrm{p}$.

SCARPA, A.; GUERCI, A. Depigmenting procedures and drugs employed by melanoderm populations. Journal of Ethnopharmacology, Pretoria, v. 19, p. 17-66, 1987.

SILVA, V. G. Candomblé e umbanda: caminhos da devoção brasileira. São Paulo: Ática, 1994. 149 p.

TEIXIDOR-TONEU, I.; MARTIN, G. J.; OUHAMMOU, A.; PURI, R. K.; HAWKINS, J. A. An ethnomedicinal survey of a tashelhit-speaking community in the high atlas, Morocco. Journal of Ethnopharmacology, Pretoria, v. 188, p. 96-110, 2016.

TURNER, V. W. O processo ritual: estrutura e antiestrutura. Petrópolis: Vozes, 2013. 245 p. 
VITALINI, S.; PURICELLI, C.; MIKEREZI, I.; IRITI, M. Plants, people and traditions: ethnobotanical survey in the lombard stelvio national park and neighbouring areas (Central Alps, Italy). Journal of Ethnopharmacology, Pretoria, v. 173, p. 435-458, 2015.

WALMIR JÚNIOR. Racismo religioso é o retrato da intolerância no Brasil. 2016. Disponível em: https://www.geledes.org.br/racismo-religioso-e-o-retrato-daintolerancia-no-brasil/. Acesso em: 06 dez 2020.

WFO. World Flora Online. Disponível em: http://www.worldfloraonline.org. Acesso em: 05 dez 2020.

ZEGGWAGH, A. A.; LAHLOU, Y.; BOUSLIMAN, Y. Enquetesur les aspects toxicologiques the la phytoterapie utilisee par un herboriste à Fes, Maroc. Pan African Medical Journal, Kampala, v. 14, n. 125, p. 1-6, 20

Recebido em: 16/02/2021

Aprovado em: 11/03/2021

Publicado em: 18/06/2021 